\title{
Lacunar syndromes due to brainstem infarct and haemorrhage
}

\author{
CY HUANG, E WOO, YL YU, FL CHAN* \\ From the University Department of Medicine and the Department of Diagnostic Radiology, ${ }^{*}$ Queen Mary \\ Hospital, Hong Kong
}

SUMMARY Nine patients with brainstem infarct and two with brainstem haemorrhage presented with pure motor stroke, pure supranuclear facial palsy, sensorimotor stroke or ataxic hemiparesis. Despite the clinical similarity with hemispheric lacunes, brainstem infarcts causing lacunar syndromes probably have a greater tendency to progress. Small brainstem haemorrhages should also be considered as a cause of lacunar syndromes and the difficulty in differentiating them from small infarcts without CT is emphasised.

Lacunar syndromes have been described in vascular lesions of the brainstem and hemisphere. Most clinico-radiological studies using computed tomography $(C T)$ have, however, concentrated on hemisphere lesions ${ }^{12}$ with only sporadic reports of brainstem lesions. We described here our experience in 11 cases presenting with lacunar syndromes due to infarct or haemorrhage in the brainstem.

\section{Patients and methods}

Eleven patients were seen with CT evidence of a brainstem vascular lesion and clinical features consistent with pure motor stroke, $^{3}$ supranuclear facial palsy, ${ }^{4}$ sensorimotor stroke, ${ }^{5}$ or ataxic hemiparesis ${ }^{6}$ (table). Patient 11 with ataxic hemiparesis was reported previously and will not be described here. ${ }^{7}$ Computed tomography (CT) of the brain was obtained using a GE 9800 scanner with contiguous $10 \mathrm{~mm}$ slices.

Four patients presented with pure motor stroke. Three were due to paramedian infarcts in the basis pontis (Patients 1 to 3, figs 1-3), and another had a small tegmental haemorrhage (Patient 4, fig 4). The infarct patients showed progressive deterioration after onset of the symptoms, whilst the haemorrhage patient actually noted improvement of symptoms by the time he arrived at the hospital. A case of pure supranuclear facial palsy due to a paramedian pontine infarct was also seen (Patient 5, fig 5). Four patients (Patients 6 to 9, fig 6 to 9), three having ischaemic and one haemorrhagic lesions, presented with a sensorimotor stroke. The ischaemic lesions were bigger than those of pure motor stroke, and in two cases, separate adjacent lesions were seen.

Address for reprint requests: Dr C Y Huang, Department of Medicine, University of Hong Kong, Queen Mary Hospital, Hong Kong.

Received 15 September 1987.

Accepted 1 October 1987
Progression of deficit was noted in two of the ischaemic cases. Two patients had ataxic hemiparesis, with one as the dysarthria-clumsy hand variant (Patients 10 and 11, fig 10). The lacunes in these two patients were situated in the ventrolateral aspect of the brainstem.

\section{ILLUSTRATIVE CASES}

Pure motor stroke

Case 4: TPC, a 52 year old Chinese male was admitted with a sudden onset of left hemiparesis associated with transient diplopia, vomiting but no headache. By the time of admission, he was better subjectively. There was a history of heavy

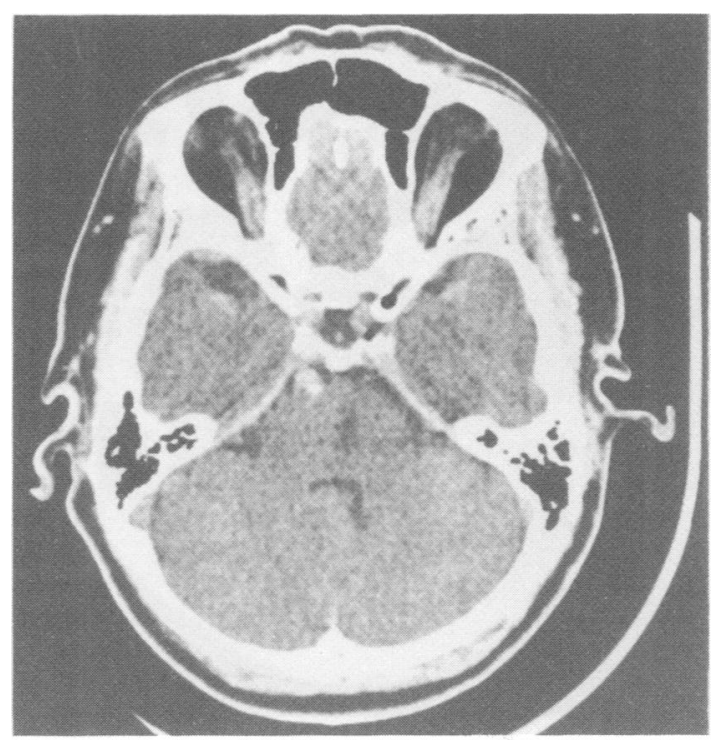

Fig $1 L M N, 67$ year old female with pure motor stroke. 
Table Summary of clinical features

\begin{tabular}{|c|c|c|c|c|c|c|c|c|c|c|}
\hline \multirow[b]{2}{*}{ Patient } & \multirow[b]{2}{*}{$\begin{array}{l}\text { Sex/Age } \\
(y r)\end{array}$} & \multirow[b]{2}{*}{ Pathology } & \multicolumn{3}{|l|}{ Motor } & \multirow[b]{2}{*}{$\begin{array}{l}\text { Sensory } \\
\text { Impairment }\end{array}$} & \multirow[b]{2}{*}{ Ataxia } & \multirow[b]{2}{*}{$\begin{array}{l}\text { Other Symptoms/ } \\
\text { Signs }\end{array}$} & \multirow{2}{*}{$\begin{array}{l}\text { Progression of } \\
\text { Neurological } \\
\text { deficits }\end{array}$} & \multirow[b]{2}{*}{ Risk factof } \\
\hline & & & $\begin{array}{l}\text { Facial } \\
\text { Weakness }\end{array}$ & $\begin{array}{l}U L \\
\text { power }\end{array}$ & $\begin{array}{l}L L \\
\text { power }\end{array}$ & & & & & \\
\hline \multicolumn{11}{|c|}{ Pure motor stroke } \\
\hline $1 \mathrm{LMN}$ & $\mathrm{F} / 67$ & Infarct & - & 2 & 2 & - & - & - & + & Hypertens迎 \\
\hline $2 \mathrm{CWK}$ & $\mathrm{F} / 61$ & Infarct & - & 4 & 4 & - & - & - & + & Hypertensior \\
\hline 3 LKL & $\mathrm{F} / 42$ & Infarct & + & 4 & 4 & - & - & - & + & Hypertension \\
\hline $4 \mathrm{TPC}$ & $\mathrm{M} / 52$ & Haemorrhage & - & 4 & 4 & - & - & Vomiting, Diplopia & - & $\begin{array}{l}\text { Hypertens } \\
\text { smoking }\end{array}$ \\
\hline \multicolumn{11}{|c|}{ Pure supranuclear facial palsy } \\
\hline $5 \mathrm{CS}$ & $M / 65$ & Infarct & + & 5 & 5 & - & - & Dysarthria & - & Smoking $\frac{\overline{\bar{\omega}}}{\vec{J}}$ \\
\hline \multicolumn{11}{|c|}{ Sensorimotor stroke } \\
\hline $6 \mathrm{CL}$ & $\mathrm{F} / 58$ & Infarct & - & 0 & 0 & Proprioceptive & - & Dysarthria & + & Diabetes \\
\hline 7 LY & $\mathrm{F} / 70$ & Infarct & - & 0 & 3 & Nociceptive & - & Vertigo & - & $-\quad \frac{\omega}{\omega}$ \\
\hline $8 \mathrm{NCS}$ & $\mathrm{F} / 58$ & Infarct & + & 0 & 0 & $\begin{array}{l}\text { Nociceptive } \\
\text { Proprioceptive }\end{array}$ & - & Headache & + & Diabetes $\overrightarrow{0}$ \\
\hline 9 LK & $\mathrm{M} / 57$ & Haemorrhage & - & 3 & 2 & $\begin{array}{l}\text { Nociceptive } \\
\text { (UL only) }\end{array}$ & - & Vertigo & - & Hypertensior \\
\hline \multicolumn{11}{|c|}{ Ataxic hemiparesis } \\
\hline $10 \mathrm{CYC}$ & $\mathrm{M} / 62$ & Infarct & + & 4 & 5 & - & + (UL only) & Dysarthria & - & Hypertensigr $r$ \\
\hline $11 \mathrm{HC}$ & $\mathbf{F} / 52$ & Infarct & - & 3 & 4 & - & + & - & - & $\begin{array}{l}\text { Diabetes, } \overline{0} \\
\text { Hypertensior }\end{array}$ \\
\hline
\end{tabular}

Motor power in limbs graded according to MRC scale: $\mathrm{UL}=$ upper limb, $\mathrm{LL}=$ lower limb, $+=$ present, $-=\mathrm{absent}$.

cigarette smoking and of irregularly-treated hypertension for 2 years. On examination he was found to have a mild left hemiparesis of MRC grade 4 in both upper and lower limbs and normal facial symmetry. Tendon reflexes and plantar responses were normal bilaterally, as were the sensorium and the rest of the neurological examination. Blood pressure was $150 / 90 \mathrm{mmHg}$. CT showed a small right lateral tegmental pontine haemorrhage (fig 4). There was no progression of signs and he made a complete recovery in 2 months.

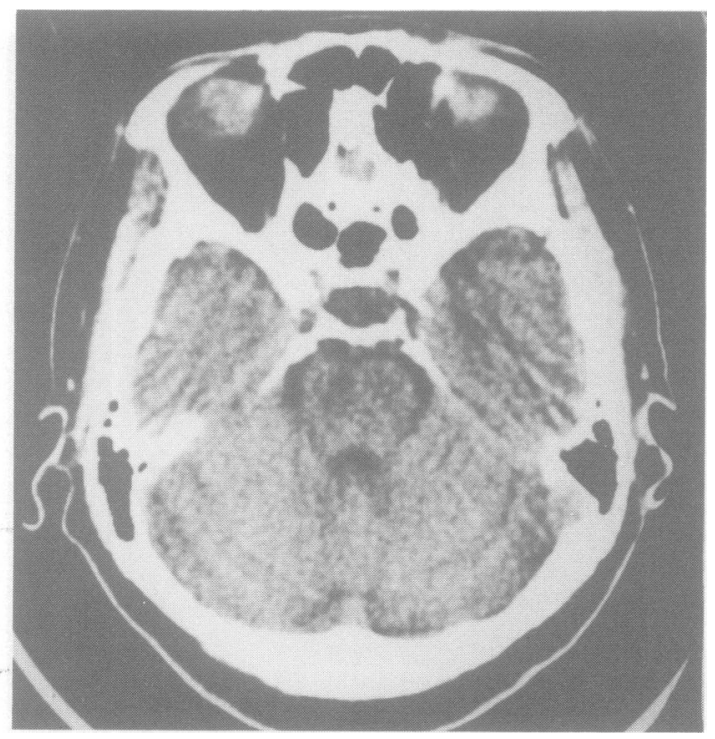

Fig $2 C W K, 61$ year old female with pure motor stroke.
Pure supranuclear facial palsy

Case 5: CS, a 65 year old Chinese male was admitted with an acute onset of slurred speech and drooling of saliva for 3 days. There was no history of vertigo, diplopia, ataxia, nausea, vomiting, limb weakness or sensory impairment음 Past health was unremarkable. He smoked 40 cigarettes day. On examination there was a mild weakness involvinge the lower half of the right face only. Frontalis and $\infty$ orbicularis oculi activity as well as taste were intact. There was a mild dysarthria present but no uvula or tongue abnor-

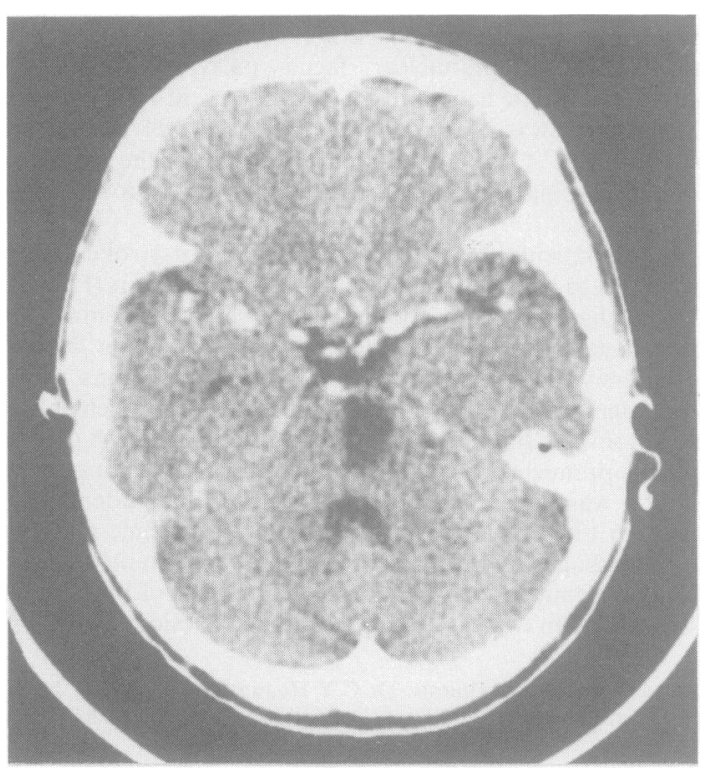

Fig $3 L K L, 42$ year old female with pure motor stroke. 

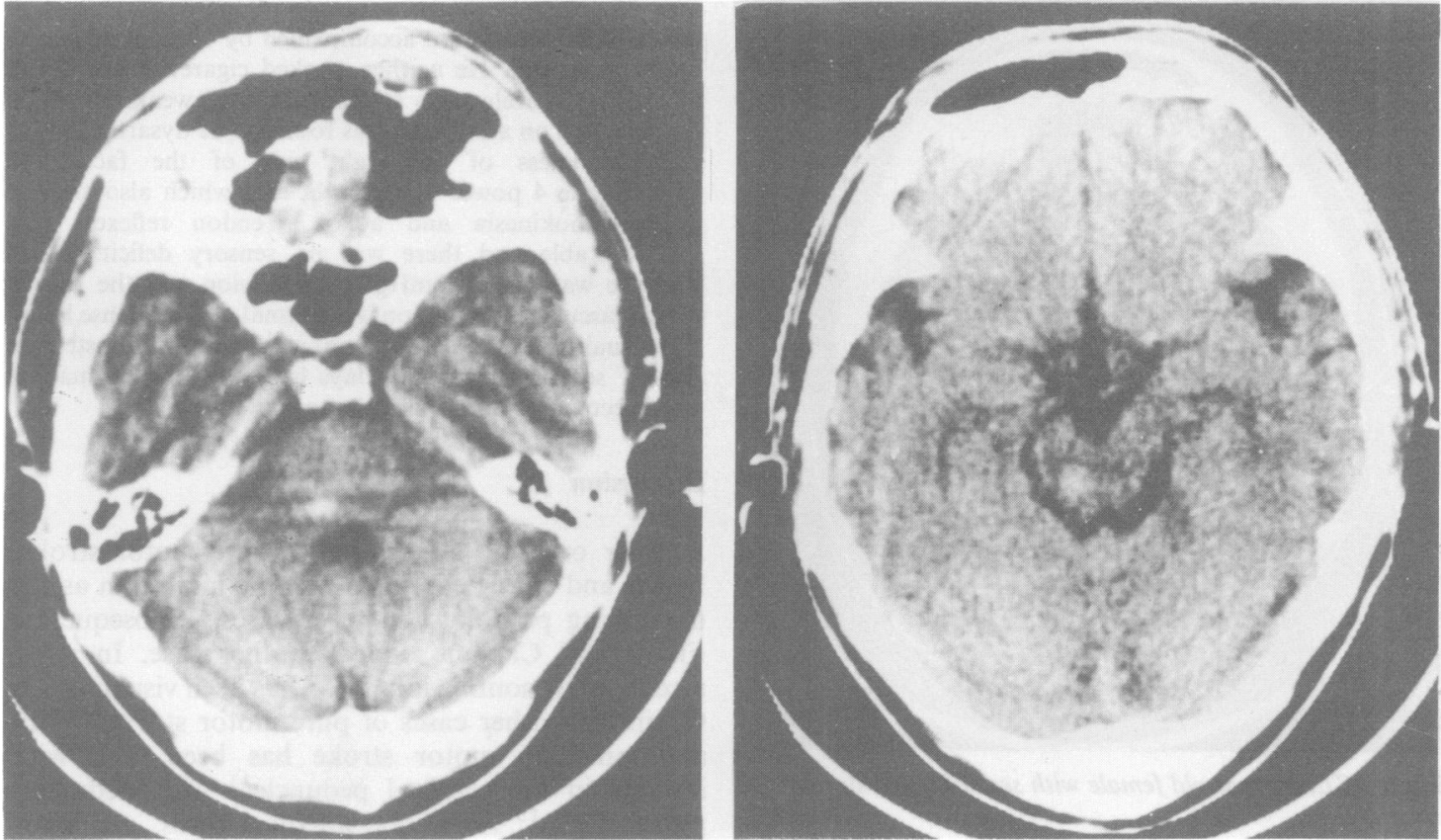

Fig 4 TPC, 52 year old male with pure motor stroke.

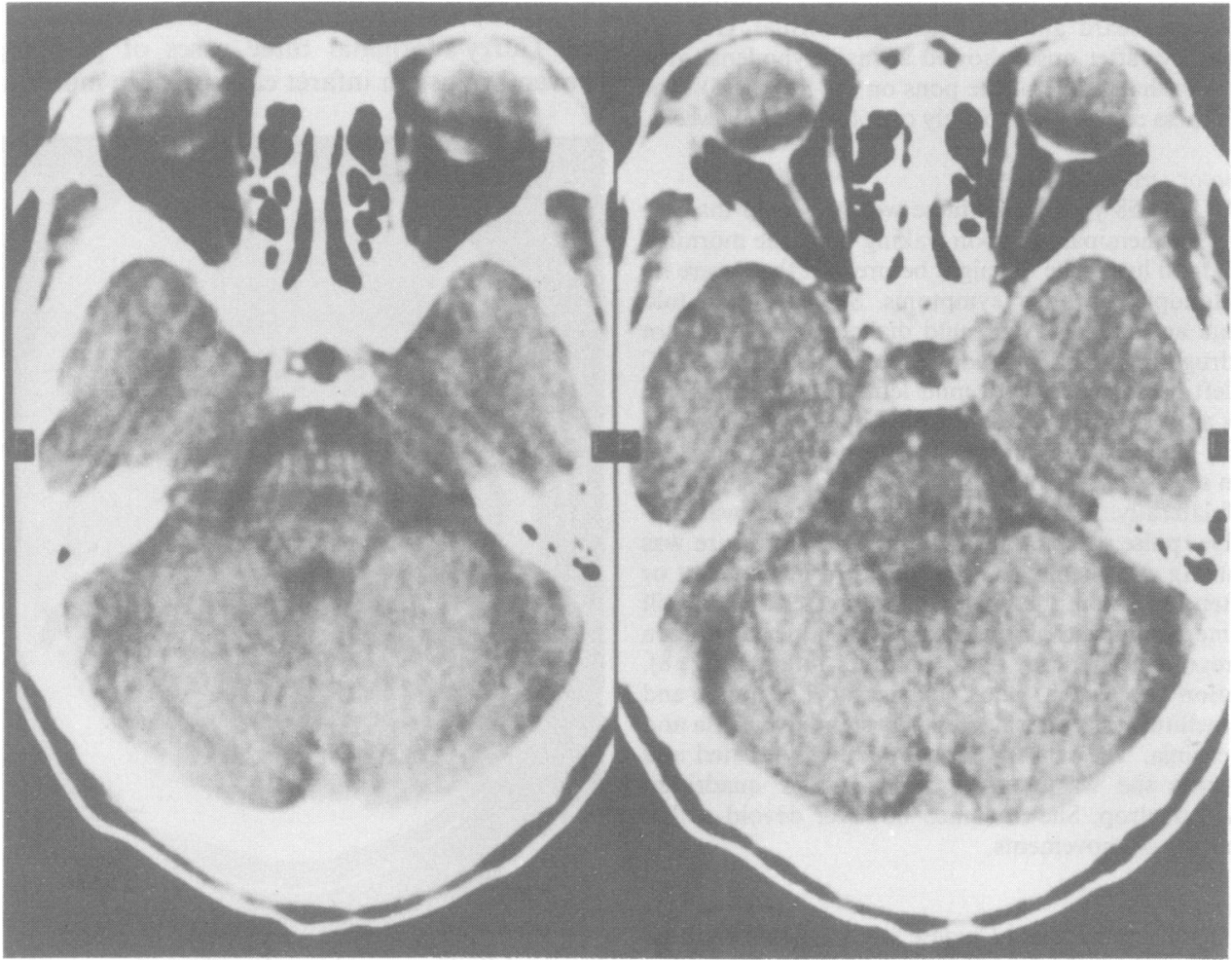

Fig 5 CS, 65 year old male with pure supranuclear facial palsy.

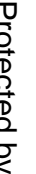




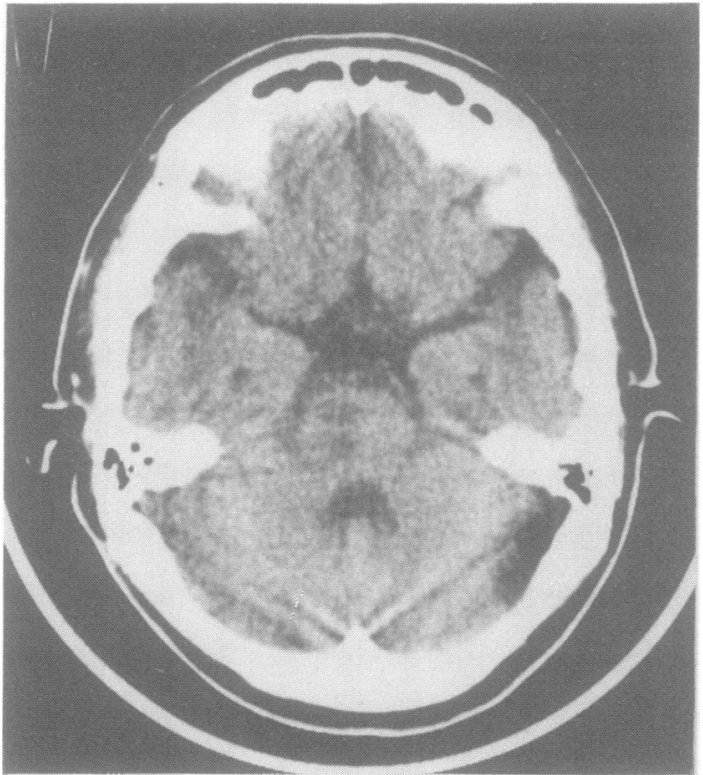

Fig 6 CL, 58 year old female with sensorimotor stroke.

mality and the gag reflex was normal. The rest of the nervous system was also normal. Blood pressure was $130 / 80 \mathrm{mmHg}$, no bruits were heard and the heart was normal. CT performed 10 days after onset showed a small hypodense area just lateral to the middle of the pons on the left (fig 5). The facial weakness resolved completely over the next few weeks.

\section{Sensorimotor stroke}

Case 8: NCS, a 58 year old Chinese woman found that she had a mild left hemiparesis upon waking up in the morning. She had a mild headache the night before, but there were no vertigo, diplopia, or other symptoms. She had been told some years ago that she had mild diabetes which did not require drug treatment. On admission there was a MRC grade 3 left hemiparesis, with mild left supranuclear facial weakness and dysarthria, accompanied by decreased touch, pin prick, temperature and position sense on the left. Vibration sense was absent below the knees and distal to the elbows bilaterally. Cardiovascular examination was unremarkable: pulse was $80 / \mathrm{min}$ regular, blood pressure was $150 / 80 \mathrm{mmHg}$ and there was no bruit heard in the heart or neck. After admission, the weakness progressed steadily till she became hemiplegic by the next day. CT performed on day 2 revealed a large right pontine infarct (fig 8). Investigation revealed a blood glucose of $12.9 \mathrm{mmol}$ and diabetes mellitus was confirmed by persistent glycosuria and hyperglycaemia. The sensory deficits gradually abated and at 3 months she was able to walk with a quadripod despite a foot drop. She remained however devoid of left hand function or movements.

Ataxic hemiparesis

Case 10: CYC, a 62 year old Chinese male was known to be hypertensive and receiving anti-hypertensive treatment for over 20 years. He had an episode of spontaneous vertigo lasting an hour and not accompanied by other symptoms 2 years previously. He neither smoked cigarettes nor drank alcohol. He developed a sudden left sided weakness in the daytime and on admission was found to be dysarthric, with mild weakness of the right side of the face, and MRC grade 4 power in the right arm which also showed dysdiadochokinesia and ataxia. Tendon reflexes were unremarkable and there was no sensory deficit. Blood pressure was $160 / 90 \mathrm{mmHg}$ on admission and the rest of cardiovascular examination was normal. A hypodense lesion was visualised in the ventrolateral region of the brainstem on the CT scan performed 17 days later (fig 10). He made a good recovery over the next 3 months.

\section{Discussion}

In their original description of pure motor stroke, Fisher and Curry described pontine infarction as the underlying pathology in three cases. ${ }^{3}$ Subsequently Fisher and Caplan ${ }^{8}$ added another case. In more recent years, pontine infarction has been visualised on CT in four other cases of pure motor stroke. ${ }^{910}$ In addition pure motor stroke has been seen with infarcts in the cerebral peduncle ${ }^{11}$ and medullary pyramid. ${ }^{12-15}$ As in the previous cases, our three cases of pure motor stroke were found to have an ischaemic lesion in the paramedian aspect of the pons (fig 1 to 3). In addition to the motor weakness, Fishero and Curry's original three cases of pathologically proven brainstem infarct causing pure motor stroke

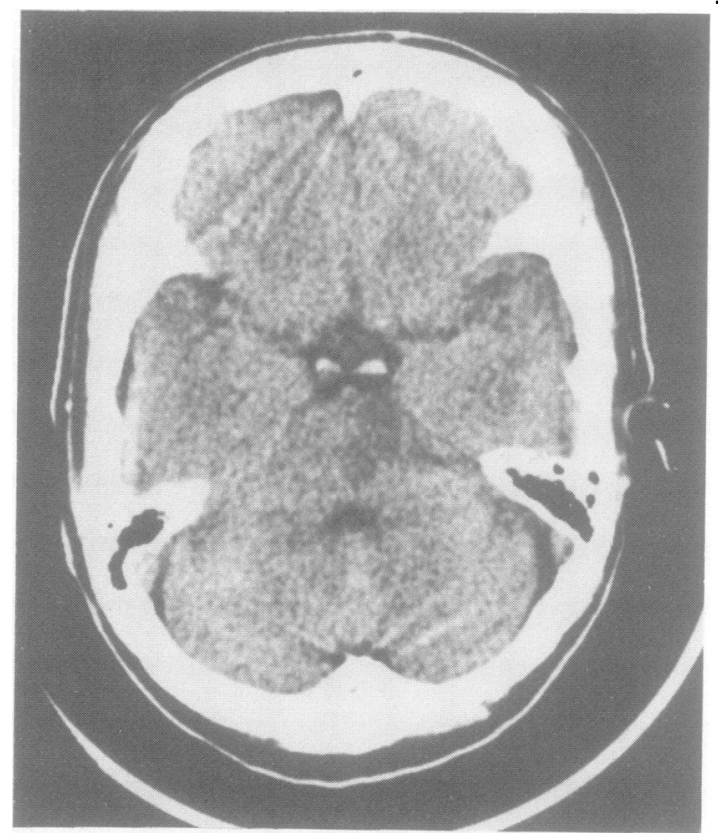

Fig $7 L Y, 70$ year old female with sensorimotor stroke. 


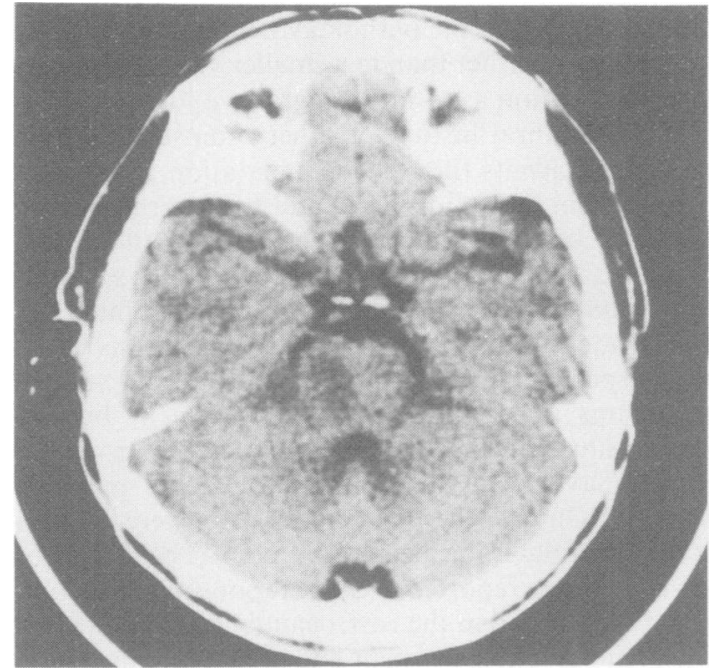

Fig 8 NCS, 58 year old female with sensorimotor stroke.

showed additional difficulty in gaze associated with horizontal nystagmus on looking away from the hemiplegic side in one and dysphagia in two. Stiller $e t$ $a l^{10}$ reported a patient who experienced episodes of transient diplopia and non-specific dizziness during the week before admission. A sensation of dizziness without vestibular signs was noted in two other patients. ${ }^{9}$ In the present series transient diplopia was noted in the case with pontine haemorrhage (Patient 4). Thus, gaze paresis away from the hemiplegia, dysphagia, and a history of diplopia would indicate a brainstem localisation for the pure motor stroke. However, there appear to be no consistent clinical

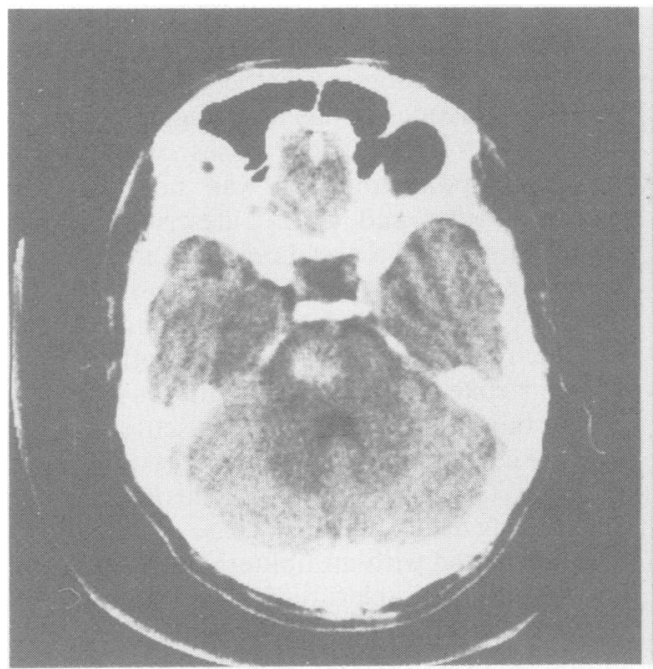

Fig $9 L K, 57$ year old male with sensorimotor stroke. signs to differentiate whether the lesion is situated in the cerebral peduncle, pons, or medulla. Of the cases studied pathologically, the responsible lesions included lacunes confined to the medullary pyramid and extending rostrocaudally for only $3 \mathrm{~mm}$ in one case and being $2 \times 1 \times 4 \mathrm{~mm}^{3}$ in another, ${ }^{14}$ and two lesions of $8 \mathrm{~mm}$ diameter in the basis pontis and extending for $7 \mathrm{~mm}$ and $14 \mathrm{~mm}$ respectively. Fisher and Caplan ${ }^{8}$ reported another case, with a pontine infarct of $10 \times 10 \times 6 \mathrm{~mm}$. Two other reports did not specify the actual lesion size. ${ }^{11}{ }^{12}$ Apart from technical difficulties, the small size of the lesions may explain why brainstem infarcts are much less often visualised in $\mathrm{CT}$.

Huang and Broe ${ }^{4}$ described cases of pure supranuclear facial palsy associated with lacunes in the internal capsule and corona radiata, while Puvanendran et $a l^{16}$ had earlier postulated that brainstem corticobulbar tract involvement could probably give rise to the same syndrome, and drew attention to Dejerine's original description of pontomedullary fibre bundles which leave the pyramidal tracts to supply the facial nucleus. Kuypers ${ }^{17}$ described the corticobulbar tracts in humans and also pointed out that the supranuclear fibres to the facial nucleus depart from the pyramidal tract only close to the nucleus in the caudal part of the pons and approach the nucleus medially. In case 5 of the present series, CT revealed a small lacune almost in the middle of the lower pons, a site consistent with the previous anatomical studies (fig 5).

Until recently there has been uncertainty as to whether sensorimotor stroke could be considered a lacunar syndrome. We have shown that sensorimotor stroke due to a hemisphere lacune is best diagnosed

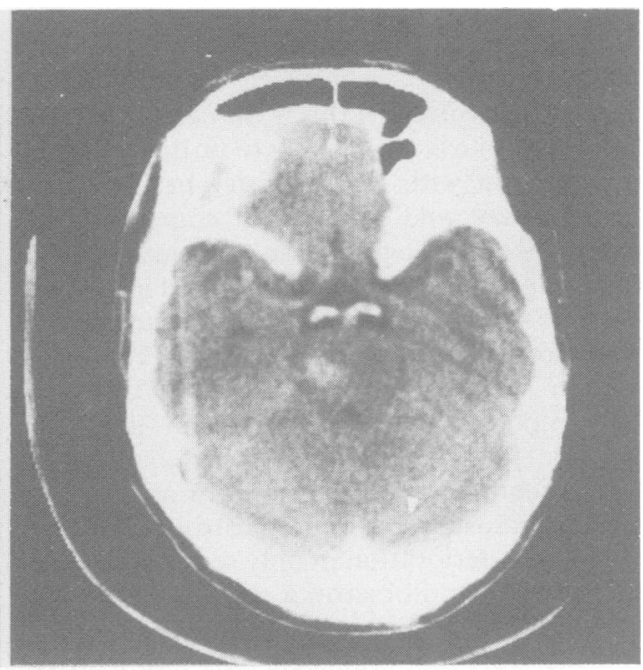




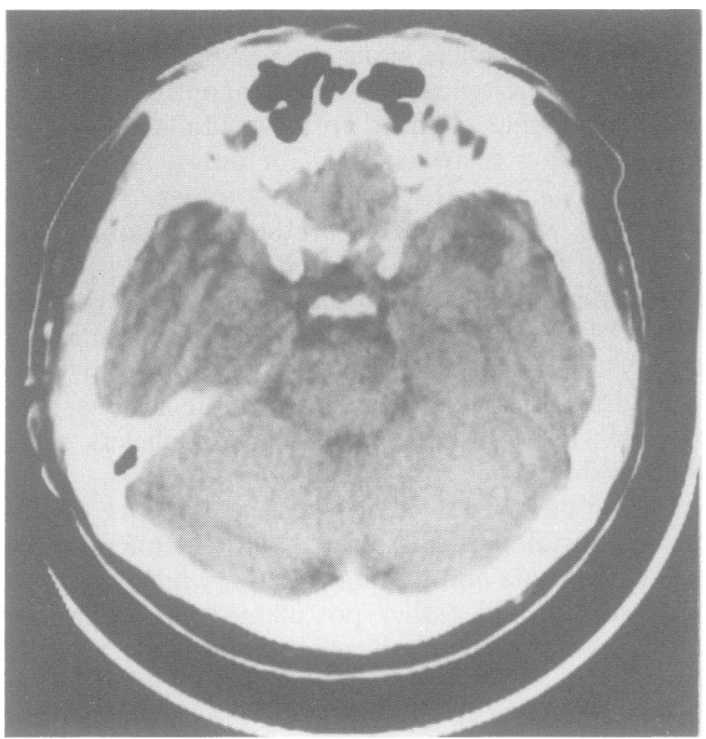

Fig 10 CYC, 52 year old male with dysarthria-clumsy hand syndrome.

only in those patients with incomplete motor or sensory impairment. ${ }^{5}$ Using this more stringent definition, capsular lacunes can be differentiated from brainstem and large hemispheric lesions presenting as sensorimotor stroke. It is interesting to note that whilst all the cases of pontine infarction causing pure motor stroke on CT had been due to a single lesion, two of the sensorimotor stroke cases showed instead two separate hypodense areas (figs 6, 7). This may suggest that the paramedian artery territory includes mainly the corticospinal tract while the medial lemniscus fibres receive good collateral supply from the circumferential branches so that sensory involvement is only present when more than one branch vessel is involved. If this is the case, brainstem sensorimotor stroke is more likely to be due to a nonlacunar infarction with more sinister basilar artery trunk involvement and the clinical course of such cases is more likely to be progressive. In this regard, it is worth noting that progression was noted in all three cases of pure motor stroke (cases 1 to 3 ) and in two cases of sensorimotor stroke (cases 6, 8). Progressive deterioration was also noted in six of the eight previously reported cases of brainstem ischaemia causing pure motor stroke. ${ }^{389}$ In comparison, Rascol et al reported progression in 15 of 28 of the cases of non-brainstem pure motor stroke. We have similarly noted deterioration in only seven of 42 cases of ischaemic pure motor stroke who did not have demonstrable brainstem lesion (unpublished data). It is possible therefore that brainstem pure motor stroke is also more prone to progressive deterioration, perhaps related to the pathology being situated in the basilar artery rather than in a smaller vessel. This may have implication as to more aggressive forms of therapy. The natural history of other brainstem lacunar syndromes awaits further documentation.

Brainstem infarction ${ }^{71819}$ and haemorrhage ${ }^{20-23}$ have also been seen as the underlying vascular lesion in ataxic hemiparesis and its variant, dysarthriaclumsy hand syndrome. Huang and $\mathrm{Lui}^{6}$ pointed out that a pontine location for ataxic hemiparesis could be suspected when there were accompanying nystagmus and cranial nerve involvement but no sensory impairment. Somatosensory evoked potential studies have been normal in two of the previous cases. ${ }^{719}$ On CT, the ischaemic lesions were all seen in the ventrolateral aspect of the pons. The lesions of each of these reported cases of pontine infarction have been limited in the rostrocaudal direction to less than $10 \mathrm{~mm}$. The consistent site of the lesions would support the concept that corticopontine and corticospinal projections are interrupted as a result of occlusion of a lateral penetrator branch arising from the short circumferential branches of the basilar artery.

Brainstem pathology producing pure sensory stroke has only been reported in one case, a case of midbrain haemorrhage. ${ }^{24}$ The patient complained of numbness and tingling in the arm and leg but did not 8 have any abnormality on sensory testing. The haemorrhage was seen in the dorsolateral midbrain at the site of the medial lemniscus and spinothalamic tract. The small size of any lesion causing pure sensory stroke is probably the reason why ischaemic lesions have not been visualised so far with CT in the brainstem. Hopefully magnetic resonance imaging will be able to detect such cases in future.

Lipohyalinolysis is the major vascular pathology in capsular lacunes. Whether the same applies to brainstem lacunes as has been suggested ${ }^{25}$ is far from conclusive. In the few cases with pathological findings, lipohyalinolysis was not the prominent feature. Fisher and Curry ${ }^{3}$ described two cases of pure motor stroke and brainstem infarct associated with basilar artery atherosclerosis. Fisher and Caplan ${ }^{8}$ found occlusion by atheromatous plaque of a branch of the basilar artery in another case of pure motor stroke. In Ho's case, ${ }^{9}$ the basilar artery was patent but atherosclerotic. No vascular occlusion was found and the presence of hyalinised vessels close to the infarct suggested probable thrombosis of a small penetrating artery. Ropper's case of medullary lacune was associated with an obliterated penetrating artery and severe atherosclerotic disease of the vertebral and basilar artery.$^{14}$ The case of medullary pyramidal infarction described by Chokroverty et al had atheromatous plaques scattered throughout the major 
cerebral arteries, ${ }^{12}$ whilst the case studied by $\mathrm{Ho}$ and Meyer had patent vertebral arteries and basilar arteries with narrowing of the lumen by patchy areas of calcified atheromatous changes. ${ }^{15}$ Thus, basilar artery atherosclerosis appears to accompany brainstem infarcts frequently even when they present clinically as lacunar syndromes. Indeed, there is at present no pathological correlation for the CT visualised infarcts. Whether they are really lacunes or much larger lesions due to occlusion of more than one vessel remains to be answered.

Prior to the availability of CT the prognosis of brainstem haemorrhage had been held to be dismal. Since the advent of CT more benign cases have been described. ${ }^{26} 27 \mathrm{~A}$ lateral tegmental brainstem haemorrhage syndrome has been recognised featuring ipsilateral conjugate gaze palsy, ipsilateral internuclear ophthalmoplegia, a small reactive pupil, ipsilateral ataxia and contralateral sensorimotor impairment. ${ }^{26}$ The present cases (Patients 4 and 9) and the others in the literature underline the even more benign presentation of brainstem haemorrhage, presenting as pure motor stroke, ${ }^{28}$ pure sensory stroke, ${ }^{24}$ sensorimotor stroke, ${ }^{23}$ or ataxic hemiparesis. ${ }^{20-23}$ It is noteworthy that there were no useful symptoms or signs in our two cases or those in the literature which would allow confident separation of these small haemorrhages from ischaemic brainstem lesions presenting as lacunar syndromes. The dorsolateral location of most of these haemorrhages would suggest that they are due. to rupture of the circumferential branches rather than the paramedian arteries. Unlike ischaemic lesions, the clinical syndromes did not correspond to sites of haemorrhages, thus suggesting that pressure effect rather than tissue destruction may have been responsible for the symptoms and signs.

\section{References}

1 Nelson RF, Pullicino P, Kendall BE, Marshall J. Computed tomography in patients presenting with lacunar syndromes. Stroke 1980;11:255-61.

2 Donnan GA, Tress BM, Bladin P. A prospective study of lacunar infarction using computerized tomography. Neurology 1982:32;49-56.

3 Fisher CM, Curry HB. Pure motor hemiplegia of vascular origin. Arch Neurol 1965;13:30-44.

4 Huang CY, Broe G. Isolated facial palsy: a new lacunar syndrome. J Neurol Neurosurg Psychiatry 1984;47:84-6.

5 Huang CY, Woo E, Yu YL, Chan FL. When is sensorimotor stroke a lacunar syndrome? J Neurol Neurosurg Psychiatry 1987;50:720-6.

6 Huang CY, Lui FS. Ataxic-hemiparesis, localization and clinical features. Stroke 1984;15:363-5.

7 Huang CY, Chan KH. Pontine ataxic hemiparesis, a lateral penetrator syndrome? J Neurol Neurosurg Psychiatry 1984;47:1046-7.

8 Fisher CM, Caplan LR. Basilar artery branch occlusion: A cause of pontine infarction. Neurology 1971;21:900-5.

9 Rascol A, Clanet M, Manelfe C, Guiraud B and Bonafe A. Pure motor hemiplegia: CT study of 30 cases. Stroke 1982;13:11-7.

10 Stiller J, Shanzer S, Yang W. Brainstem lesions with pure motor hemiparesis. Computed tomographic demonstration. Arch Neurol 1982;39:660-1.

11 Ho KL. Pure motor hemiplegia due to infarction of the cerebral peduncle. Arch Neurol 1982;39:524-6.

12 Chokroverty S, Rubino FA, Haller C. Pure motor hemiplegia due to pyramidal infarction. Arch Neurol 1985;32:647-8.

13 Leestma JE, Noronha A. Pure motor hemiplegia, medullary pyramid lesion, and olivary hypertrophy. J Neurol Neurosurg Psychiatry 1976;39:877-84.

14 Ropper AH, Fisher CM, Kleinman GM. Pyramidal infarction in the medullar: A cause of pure motor hemiplegia sparing the face. Neurology 1979;29:91-5.

15 Ho KL, Meyer KR. The medial medullary syndrome. Arch Neurol 1981;38:385-7.

16 Puvanendran K, Wong PK, Ransome GA. Syndrome of Dejerine's fourth reich. Acta Neurol Scand 1978;58:345-53.

17 Kuypers HGJ. Corticobulbar connexions to the pons and lower brain-stem in man. An anatomical study. Brain 1958;81: 364-88.

18 Fisher CM. Ataxic hemiparesis. A pathological study. Arch Neurol 1978:35:126-8.

19 Delgado G, Gallego J, Zubieta JL. High-resolution CT scan in pontine ataxic hemiparesis. $J$ Neurol Neurosurg Psychiatry 1985;48:1069.

20 Schnapper RA. Pontine hemorrhage presenting as ataxic hemiparesis. Stroke 1982;13:518-9.

21 Tuhrim S, Yang WC, Rubinowitz H, Weinberger J. Primary pontine hemorrhage and the dysarthria-clumsy hand syndrome. Neurology 1982;32:1027-8.

22 Kobatake K, Shinohara Y. Ataxic hemiparesis in patients with primary pontine hemorrhage. Stroke 1983;14:762-4.

23 Mori E, Tabuchi M, Yamadori A. Lacunar syndrome due to intracerebral hemorrhage. Stroke 1985;16:454-9.

24 Tuttle PV, Reinmuth OM. Midbrain hemorrhage producing pure sensory stroke. Arch Neurol 1984;41:794-5.

25 Fisher CM. The arterial lesions underlying lacunes. Acta Neuropathol (Berl) 1969;12:1-15.

26 Caplan LR, Goodwin JA. Lateral tegmental brainstem hemorrhages. Neurology 1982;32:252-60.

27 Masiyama S, Niizuma H, Suzuki J. Pontine haemorrhage: a clinical analysis of 26 cases. $J$ Neurol Neurosurg Psychiatry 1985;48:658-62.

28 Lee KY, Lie SK, Chiang TR. Small intracerebral hemorrhage clinically simulating lacunar infarction. $J$ Formosan Med Assoc 1983;82:993-1000. 